\title{
Lymphatic vessels around the uterus: D2-40 (podoplandin) immunohistochemistry using elderly cadavers
}

\author{
H. Sasaki ${ }^{1}$, Z.W. Jin'², Y.L. Liu ${ }^{3}$, Y. Jin², G. Murakami ${ }^{4}$, S.-I. Abe ${ }^{5}$ \\ ${ }^{1}$ Division of Gynaecology and Obstetrics, Ishikawa Prefectural Central Hospital, Kanazawa, Japan \\ 2Department of Anatomy, Histology and Embryology, Yanbian University Medical College, Yanji, Jilin, China \\ ${ }^{3}$ Division of Gynaecology and Obstetrics, Meihekou Central Hospital, Meihekou, Jilin, China \\ ${ }^{4}$ Division of Internal Medicine, Iwamizawa Asuka Hospital, Iwamizawa, Japan \\ ${ }^{5}$ Department of Anatomy, Tokyo Dental College, Tokyo, Japan
}

[Received: 10 June 2015; Accepted: 13 July 2015]

Using D2-40 immunohistochemistry, we examined the morphology of lymphatic vessels (LVS) in, along and around the uterus of 10 donated female cadavers (mean age, 85 years). All these women had 1 or 2 children with vaginal delivery, but the other obstetrics information was unknown. When compared with the bladder, vagina and the subperitoneal tissue, the percentage area of LVs in a $3 \times$ $2 \mathrm{~mm}$ square including the hot spot was extremely high along the uterine artery and superficial uterine vein, in spite of the silent physiology of the elderly uterus. Notably, the LVs along the uterine artery and superficial uterine vein were highly dilated and embedded in the tight connective tissue around the artery and vein. In contrast, the LVs were separated from the artery and vein in the so-called vesico-uterine ligament. Thus, surgical separation of the LVs from the artery and vein, i.e., skeletonisation, appears very difficult along the uterine artery and superficial uterine vein. This may become a major factor limiting the future application of robot-assisted surgery for uterine cancers. (Folia Morphol 2016; 75, 2: 232-239)

Key words: lymphatic vessels, artery, uterus, vagina, connective tissue

\section{INTRODUCTION}

According to classical macroscopic studies of infants and children [18, 22], the lymphatic vessels (LVs) from the uterus take several courses at various levels on the superficial (subperitoneal) to deep (sacral) side of the pelvis, although lymphatic tissues are well developed in the young. Recently, however, in an excellent injection study using fresh adult cadavers, Ercoli et al. [3] demonstrated that the supraureteric lymphatic route along the uterine artery and superficial uterine vein plays a major and critical role in metastasis of cancer from the uterine cervix, in contrast to the infraureteric route along the deep uterine vein as well as the neural paracervical route in the nerve-rich deep part of the cardinal ligament. In fact, using D2-40 immunohistochemistry of cardinal ligament specimens removed from cervical cancer patients, Hoffman et al. [8] demonstrated discontinuous micrometastases in the soft tissue around the uterine artery and superficial uterine vein and a cluster of carcinoma cells in a lymphatic vessel adjacent to the uterine artery. Recently, Weber et al. [31] confirmed similar micrometastasis in LVs in patients with endometrial cancer.

Address for correspondence: Y. Jin, MD, PhD, Department of Anatomy, Histology and Embryology, Yanbian University Medical College, No. 977 Gongyuan Road, Yanji, Jilin, 133002, China, tel: +86 433-243-5101, fax: +86 433-243-5103, e-mail: jinyu@ybu.edu.cn 
Table 1. Percentage area of lymphatic vessels at hot spots in sections

\begin{tabular}{lcccccc}
\hline Uterine arteries $^{1}$ & Vesical arteries $^{2}$ & Subperitoneal $^{3}$ & Paravaginal $^{4}$ & Myometrium & Bladder $^{5}$ & Ureter $^{5}$ \\
\hline $18.7 \pm 3.8$ & $16.0 \pm 5.1$ & $15.3 \pm 7.3$ & $19.1 \pm 5.6$ & $7.7 \pm 5.4$ & $12.7 \pm 2.4$ & $5.7 \pm 1.7$ \\
\hline
\end{tabular}

Mean \pm standard deviation (\% in $6 \mathrm{~mm}^{2}$ including accumulation of lymphatic vessels); ${ }^{1}$ Along and around the uterine artery and its branches; ${ }^{2} \mathrm{Along}$ and around the superior vesical arteries and veins; ${ }^{3}$ In the subperitoneal tissue in the broad ligament of the uterus; ${ }^{4} \mathrm{In}$ the paracolpium or paravaginal tissue $3-4 \mathrm{~cm}$ below the uterine cervix; ${ }^{5} \mathrm{In}$ smooth muscles of the bladder or ureter.

Surprisingly, the injection study by Ercoli et al. [3] using adult cadavers was the first of its kind and rather limited in scope. This situation is clearly different from other viscera, such as the lung and oesophagus [20], mammary gland [26] and stomach $[16,23]$. Thus, application of sentinel node biopsy for carcinomas of the uterus $[11,12]$ appeared to precede descriptions of normal adult anatomy of the lymphatic drainage routes. Likewise, to our knowledge, no or few studies have demonstrated the LVs around the normal uterus using D2-40 immunohistochemistry, in contrast to the extensive accumulation of knowledge of D2-40-positive LVs in other normal viscera (e.g., oesophagus [34], prostate [6], kidney [9] and others [7]). Rather than LVs around the uterus, endometrial LVs have been a major focus of interest for researchers in relation to the sexual cycle $[19,21$, 28]. Consequently, the aim of the present study was to clarify the morphology of LVs in, along and around the human uterus.

\section{MATERIALS AND METHODS}

The study was performed in accordance with the provisions of the Declaration of Helsinki 1995 (as revised in Edinburgh 2000). We examined 10 donated female cadavers ranging in age from 73 to 100 years, with a mean age of 85 years. All these women had 1 or 2 children with vaginal delivery, but the other obstetrics information was unknown. The cause of death had been ischaemic heart failure or intracranial bleeding, and we confirmed that none of the individuals had undergone surgery during life by reference to medical documents as well as macroscopic observation upon opening the abdominopelvic cavity. These cadavers had been donated to Tokyo Dental College for research and education on human anatomy, and their use for research had been approved by the university ethics committee. The cadavers had been fixed by arterial perfusion with $10 \% \mathrm{v} / \mathrm{v}$ formalin solution and stored in $50 \% \mathrm{v} / \mathrm{v}$ ethanol solution for more than 3 months. In these cadavers after fixation, we did not find any types of pelvic organ prolapse. From one cadaver, we pre- pared one large tissue block including the posterior half of the bladder, the whole uterus, the upper part of the vagina, parts of the rectum, the lower end of the ureter, and any connective tissue around these viscera. Five to seven macroscopic slices $(15 \mathrm{~mm}$ thick) were prepared from each of the hemiblocks after bisection along the midsagittal line. After performing routine procedures for paraffin-embedded histology, 5 to 7 large sections $(70 \times 50 \mathrm{~mm})$ stained with haematoxylin and eosin (HE) were prepared at 2-3-mm intervals from each of the macroslices. The sectional planes corresponded to tilted horizontal planes according to Tamakawa et al. [27] in order to show together the bladder, uterus (or vagina) and rectum in a single plane. After observation of a large section, we prepared normal-sized sections for D2-40 immunohistochemistry near the plane used for the large section. In this manner, we gradually acquired a combination of large HE histology preparations and several immunohistochemical sections ranging from the surface of the paraffin block to the bottom, covering a thickness of almost $15 \mathrm{~mm}$.

The primary antibody (monoclonal anti-human podoplanin; Nichirei D2-40, code No. 413451, Tokyo, Japan; 1:100 dilution) was used after immersion in a ligand activator (Histofine SAB-PO Kit, code No. 415211, Nichirei, Tokyo, Japan) with autoclave treatment $\left(105^{\circ} \mathrm{C}, 10 \mathrm{~min}\right)$. The second antibody (Dako Chem Mate Envision Kit, Dako, Glostrup, Denmark) was labelled with horseradish peroxidase, and antigen-antibody reactions were detected using horseradish peroxidase catalysis with diaminobenzidine. Counterstaining with haematoxylin was performed on the same samples. A negative control without a first antibody was set up for each of the specimens. Observations and photography were usually performed with a Nikon Eclipse 80, but photos at ultralow magnification (with an objective lens of less than $\times 1$ ) were taken using a high-grade flat scanner with translucent illumination (Epson ${ }^{\circledR}$ scanner GTX970).

Using cross-sectional histology with D2-40 immunohistochemistry, we took photos at hot spots of LVs [32] in each of the sections to allow compari- 

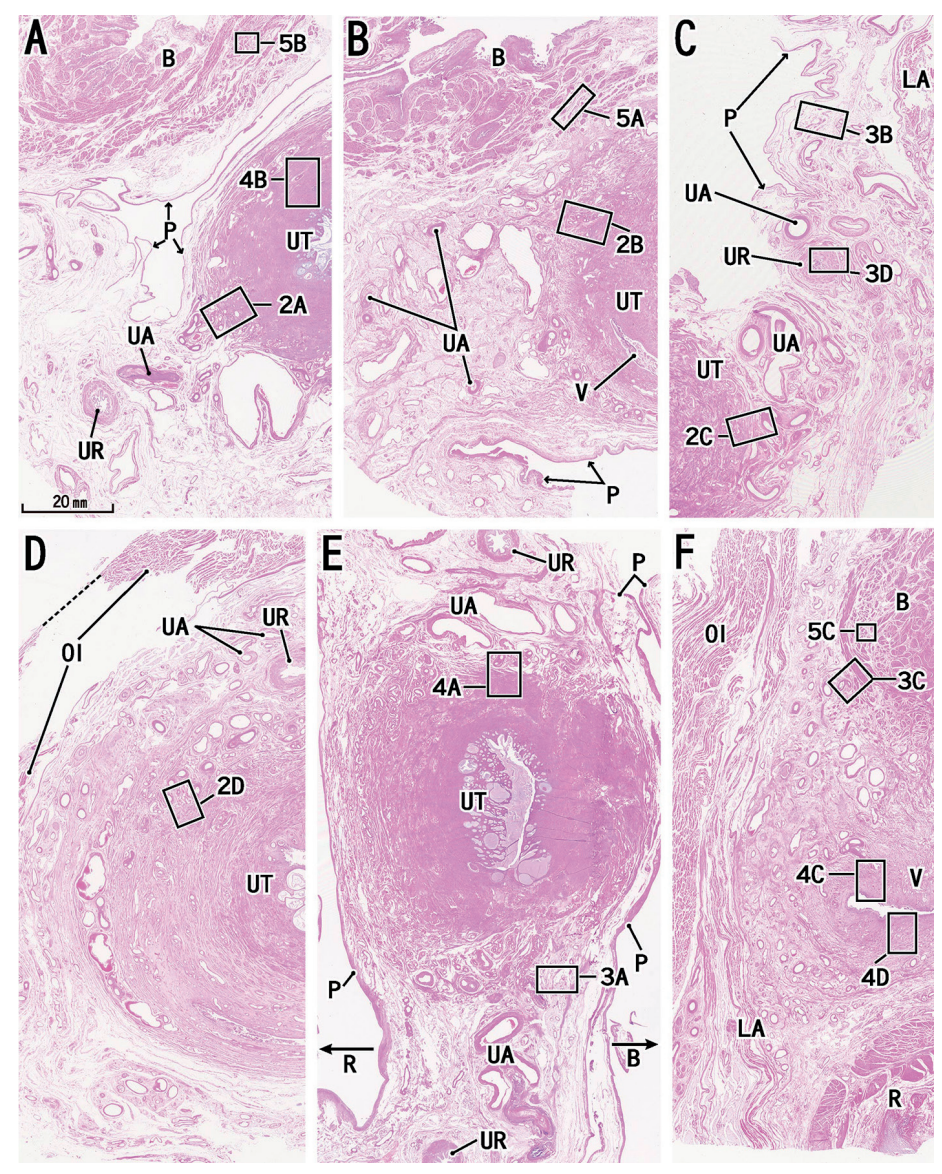

Figure 1. Topographical anatomy of the present histological sections for D2-40 immunohistochemistry; haematoxylin and eosin staining. Tilted horizontal sections A. An 83-year-old woman. The vesico-uterine pouch of the peritoneal cavity; B. An 80-year-old woman. The posterior fornix of the vagina (V); C. A 73-year-old woman. The superficial part of the cardinal ligament; D. A 73-year-old woman. A cross-section of the body of the uterus (UT); D. The obturator internus muscle (OI) was partly detached during the histological procedure; E. A 100-year-old woman. A cross-section of the broad ligament of the uterus (arrow with $\mathrm{R}$ or $\mathrm{B}$ indicates the rectal side or bladder side of the panel); $F$. A 73-year-old woman. The paracolpium or paravaginal connective tissue; B — bladder; LA — levator ani muscle; P — peritoneum; $\mathrm{R}$ - rectum; UA — uterine artery; UR - ureter.

son among the 7 sites (Table 1). After tracing of the D2-40-positive vessels, we measured them using the ImageJ version 1.45 software package (developed at the United States. National Institutes of Health and available on the internet at http://rsb.info.nih.gov/ij/). We calculated the cross-sectional area of the vessels. Analysis of pixel colour distribution allowed us to determine the percentage area concentration of each stained tissue component [13]. The present target colour was black after manual tracing of LVs on the photos. We measured the density as a percentage of black colour pixels in a rectangular area $(3 \times 2 \mathrm{~mm}$ under a $4 \times$ objective lens) of each tissue, i.e., the percentage area. The scanned (Adobe Photoshop ${ }^{\circledR}$ ) images of each site were processed using ImageJ. We deleted structures other than LVs digitally as well as manually. As a control for the uterus, we measured LVs in the ureter, bladder and rectum.

\section{RESULTS}

To provide a better understanding of the topographical anatomy of the present histological sections used for D2-40 immunohistochemistry, ultra-low magnification views of the large sections are shown in Figure 1. The present figures show 4 of 10 specimens examined, although the immunohistochemistry was performed successfully for all specimens. The immunoreactive lymphatic endothelium was often detached or fragmented, possibly due to lag-time after death, but we were able to identify the original lumen around the positive membranous structures. To improve the contrast, D2-40-positive LVs are labelled yellow in Figures $2-5$. LVs from the uterus, bladder and rectum ran along the feeding artery and drainage vein. However, along and around the vaginal wall, we often found LVs separated from or independent of the artery and vein: some LVs ran transversely along the anterior or posterior wall of the vagina, but most of them appeared to run along the longitudinal axis. Notably, in contrast to LVs from the vagina, bladder and rectum, LVs near the uterus were embedded in tight connective tissue surrounding branches of the uterine artery and tributaries of the superficial uterine vein (Figs. 2, 3D, 4A). Thus, the vascular sheath of the uterine vessels was not laminar or fascial, but appeared to be an irregularly-arrayed fibrous mass. 

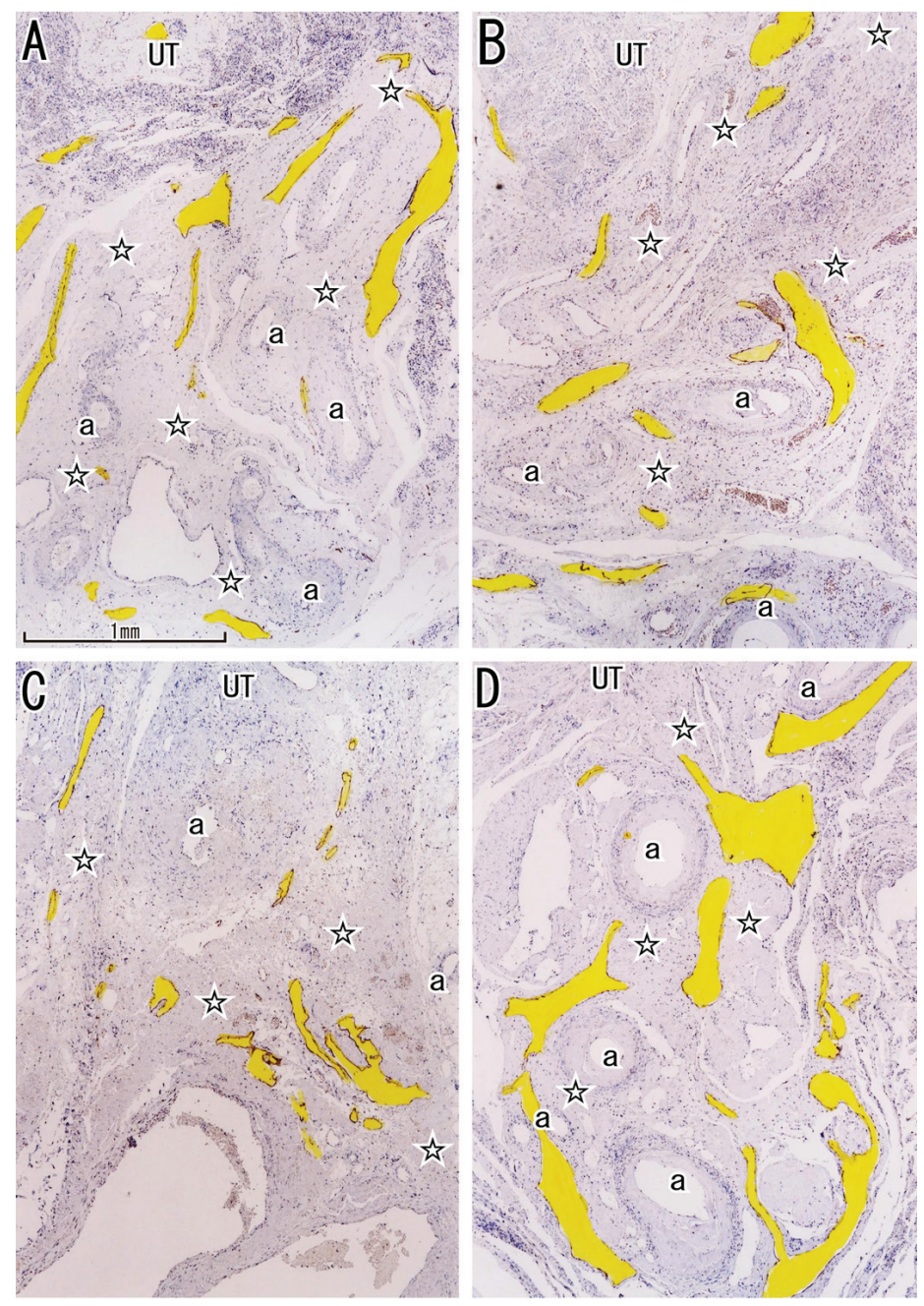

Figure 2. Lymphatic vessels along branches of the uterine artery near the uterus (UT); $\mathbf{A}$. A higher-magnification view of the square in Figure 1A (an 83-year-old woman); B. Corresponds to the square in Figure 1B (an 80-year-old woman); C. Displays the square in Figure 1C (a 73-year-old woman); D. Corresponds to the square in Figure 1D (a 73-year-old woman). Most of the lymphatic vessels (coloured yellow) are embedded in tight connective tissues (stars) along the arterial branches. Arteries are indicated by "a".

The tight connective tissue rarely contained nerves (figures not shown). Because of the highly tortuous courses of the arterial branches, LVs formed a complex network. Along the uterine arterial branches as well as in the broad ligament of the uterus, most of the LVs were dilated. In contrast, abundant thin LVs ran beneath the peritoneum (Fig. 3B).

In the bladder, intramural LVs were distributed evenly in the smooth muscle layer, ran along and around the smooth muscle bundles and joined collecting vessels along the thin intramuscular artery and vein (Fig. 5). Thus, abundant LVs were independent of, and separated from, the artery and vein in the bladder. In contrast, in the myometrium and vaginal wall, any LVs tended to run along thin arteries and veins in the smooth muscle (Fig. 4). In spite of the low percentage area in the myometrium, the percentage area of LVs along the uterine arterial branches was greater than that along the superior vesical arteries and concomitant veins (Table 1). In the loose paracolpium or paravaginal tissue, we found no significant difference in the percentage area between the anterior and posterior sides of the vagina. The percentage area of LVs was low in the ureter smooth muscle and high in the bladder smooth muscle. As the small standard deviation indicated (Table 1), the bladder intramuscular LVs were consistently well developed, in contrast to those in the myometrium. Neither valves nor smooth muscle layers were found in the present LVs in, along and around the female pelvic viscera. Likewise, we were unable to find the open initial end of LVs in the myo- and endometrium of the uterus.

\section{DISCUSSION}

The present study may be the first histological demonstration of LVs in, along and around the pelvic viscera of elderly human females without cancer. The smooth muscles of the bladder consistently contained 

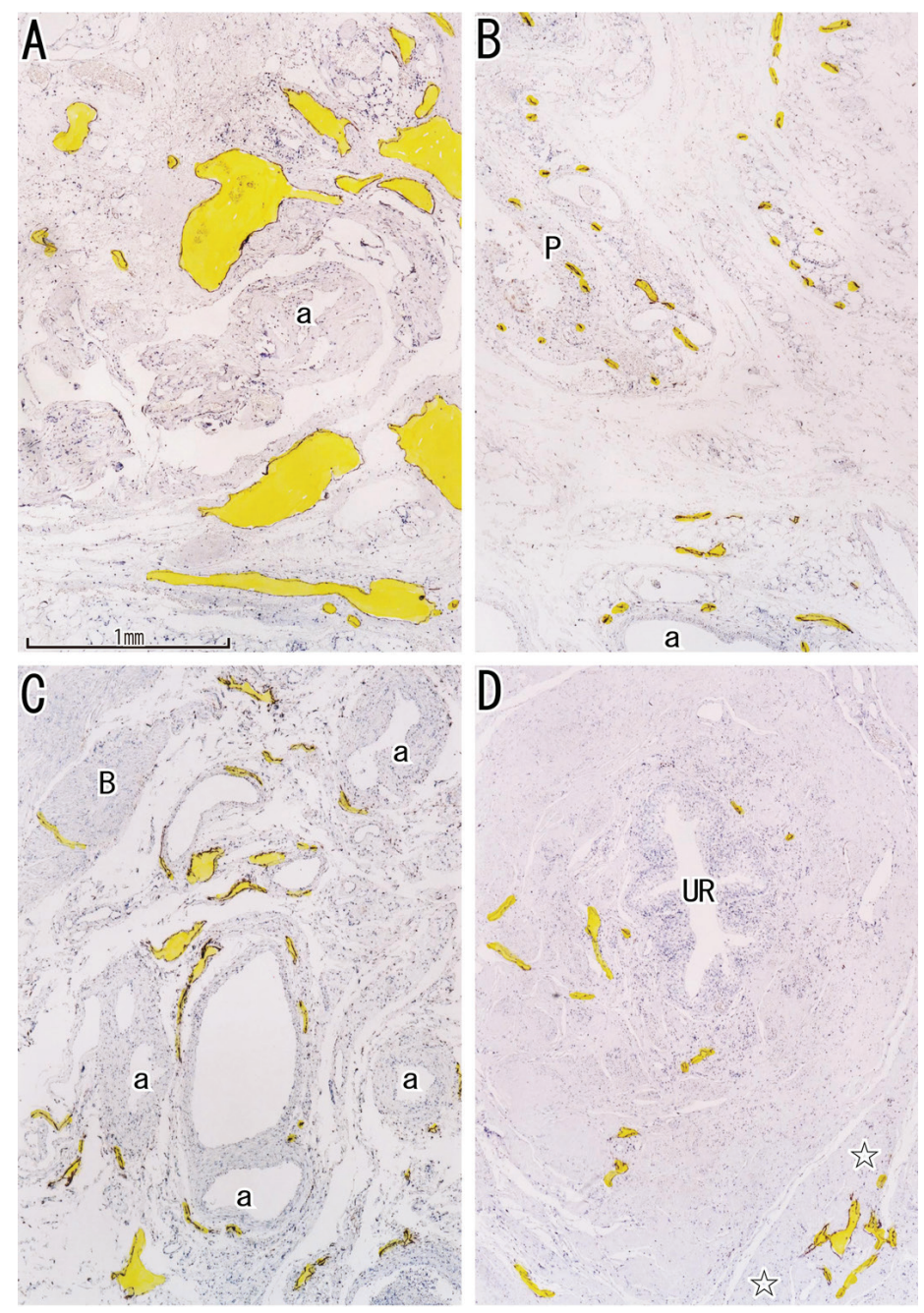

Figure 3. Lymphatic vessels beneath the peritoneum (P) and near the bladder (B) and ureter (UR); A. Displays the broad ligament of the uterus and corresponds to a higher-magnification view of the square in Figure $1 \mathrm{E}$ (a 100-year-old woman); B (subperitoneal tissue), D (the ureter). Display the squares in Figure 1C, respectively (a 73-year-old woman). Near the ureter, lymphatic vessels (coloured yellow) are embedded in tight connective tissue (stars in panel D) along an artery; C. Corresponding to the square in Figure 1F (a 73-year-old woman), exhibits lymphatic vessels along the arteries to the bladder. Arteries are indicated by "a".

abundant LVs in all parts, possibly having a functional role other than drainage, such as filling the spaces between smooth muscle bundles to maintain their configuration when relaxed. However, in spite of the advanced age of the subjects, in whom no functional demand would be expected, the LVs along and around the uterus and vagina were well developed and often dilated, occupying in high percentage area of the sections. The most striking finding was that LVs from the uterus were embedded in tight connective tissue along the uterine artery and superficial uterine vein. This vascular sheath was quite different from a loose, laminar or fascial structures surrounding the LVs from the bladder and rectum. The tight vascular sheath appeared to be absent in the so-called vesico-uterine ligament, which has been one of the important targets of dissection in radical hysterectomy, especially in Japan $[4,33]$. LVs in the female pelvis, especially around the uterus, seemed unlikely to be involved in active drainage because they lacked valves and smooth muscle in contrast to the tight sheath. Due to the physiologically silent nature of the uterus and vagina in the elderly, the abundant dilated LVs might act as a reservoir of lymph in the pelvis, although this is hypothetical. In addition, being different from Zöltzer [35], we did not find open initial ends of LVs in and around the uterus.

Ueno et al. [29] demonstrated extranodal microscopic foci of cancer metastasis in surgical specimens of perirectal loose tissues from patients with rectal cancer. These metastatic foci were discontinuous with either the lymph nodes or the primary cancer lesion. We consider these to represent metastasis along LVs independent of any artery or vein. In contrast, most of the LVs from the uterus and vagina seemed to accompany the artery and vein, and were highly dilated without any dynamic change of flow. Thus, micrometastases in LVs from carcinomas of the uter- 

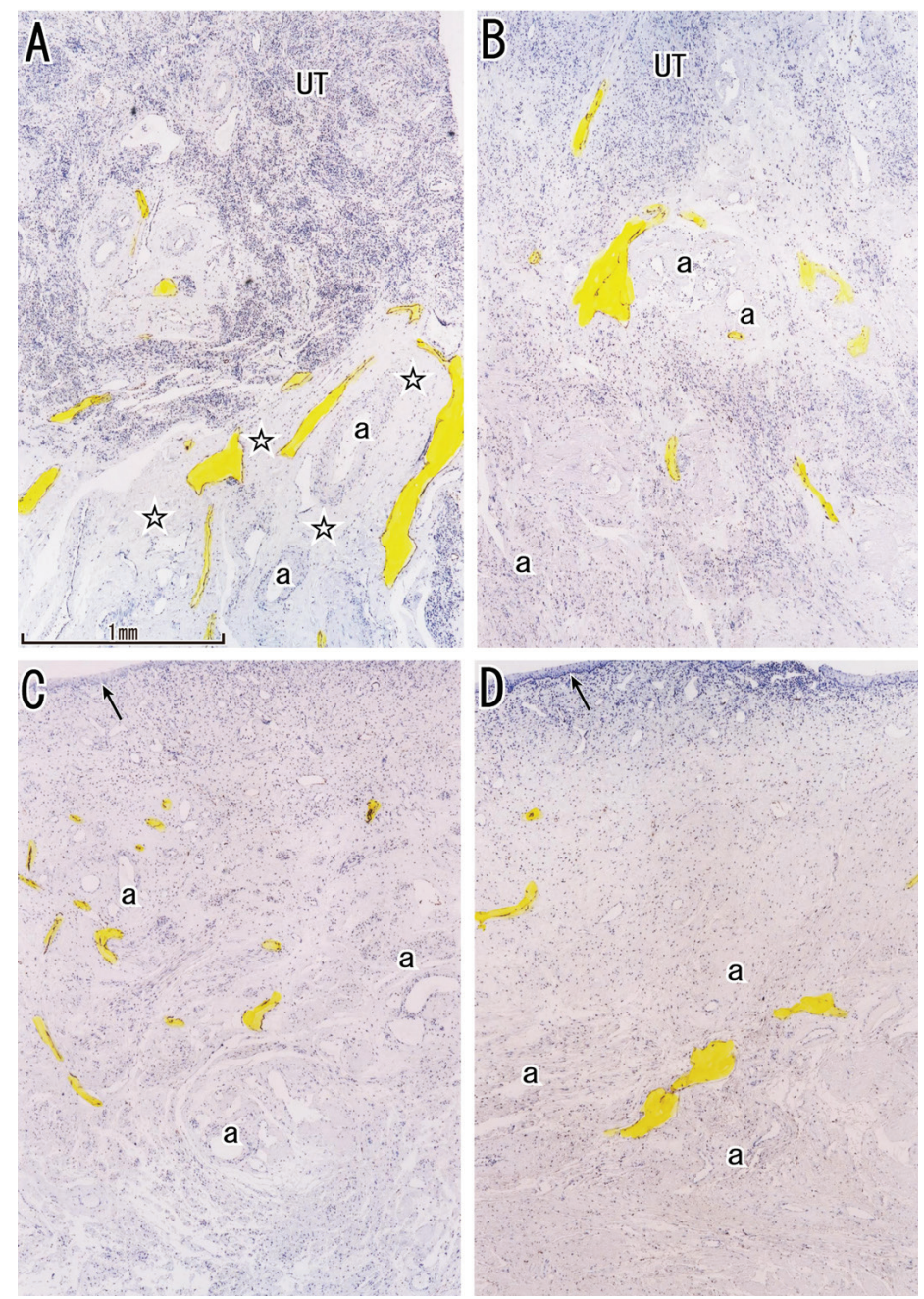

Figure 4. Lymphatic vessels in the myometrium and the vaginal wall; $\mathbf{A}$. Corresponding to a higher-magnification view of the square in Figure $1 \mathrm{E}$ (a 100-year-old woman); B. Corresponding to the square in Figure 1A (an 83-year-old woman), show lymphatic vessels in the myometrium (UT - uterus). The uterine arterial branches accompany tight connective tissue containing lymphatic vessels (stars in panel A); C (anterior wall), D (posterior wall). Corresponding to the squares in Figure $1 \mathrm{~F}$, respectively (a 73-year-old woman), display lymphatic vessels in the vaginal wall. Arrows indicate the vaginal squamous epithelium (C, D). Arteries are indicated by "a".

us, if they occur, are likely to become resident and grow. Micrometastasis along the uterine artery and superficial uterine vein has recently been considered a prognostic factor in patients with cervical and endometrial cancers $[1,10,30]$.

In general, "skeletonisation" of the artery and vein (i.e., complete removal of the vascular sheath containing LVs) appears to be one of the basic techniques for radical and extended lymphadenectomy in cancer surgery, although it often creates side effects due to removal of autonomic nerves [15]. Smith et al. [24] reported laparoscopic skeletonisation of the uterine artery for conservative management of cervical carcinoma. In their excellent injection study using fresh cadavers, Ercoli et al. [3] demonstrated the supraureteric lymphatic route along the uterine artery and superficial uterine vein plays a major and critical role in cancer metastasis from the uterine cervix. However, because of the tight entrapment of LVs close to the artery and vein, as shown in the present study, preservation of the uterine artery during complete removal of the lymphatic route would seem to be difficult. In fact, the mode for management of the uterine artery has been a focus of discussion in recent proposals for a new, more anatomically precise, classification of the radical hysterectomy procedure $[14,17]$. However, the first surgical priority in patients with cervical cancer should be minimizing the possibility of failure to remove isolated paracervical neoplastic foci. Therefore, nerve-sparing radical hysterectomy $[5,33]$ seems to offer the most effective balance between oncological safety and surgery-related complications, and would be particularly useful in selected patients such as those with early-stage disease but a high risk of paracervical involvement. Robotic lymphadenectomy including skeletonisation of the artery and vein has been tried at several hospitals for gastric cancer 

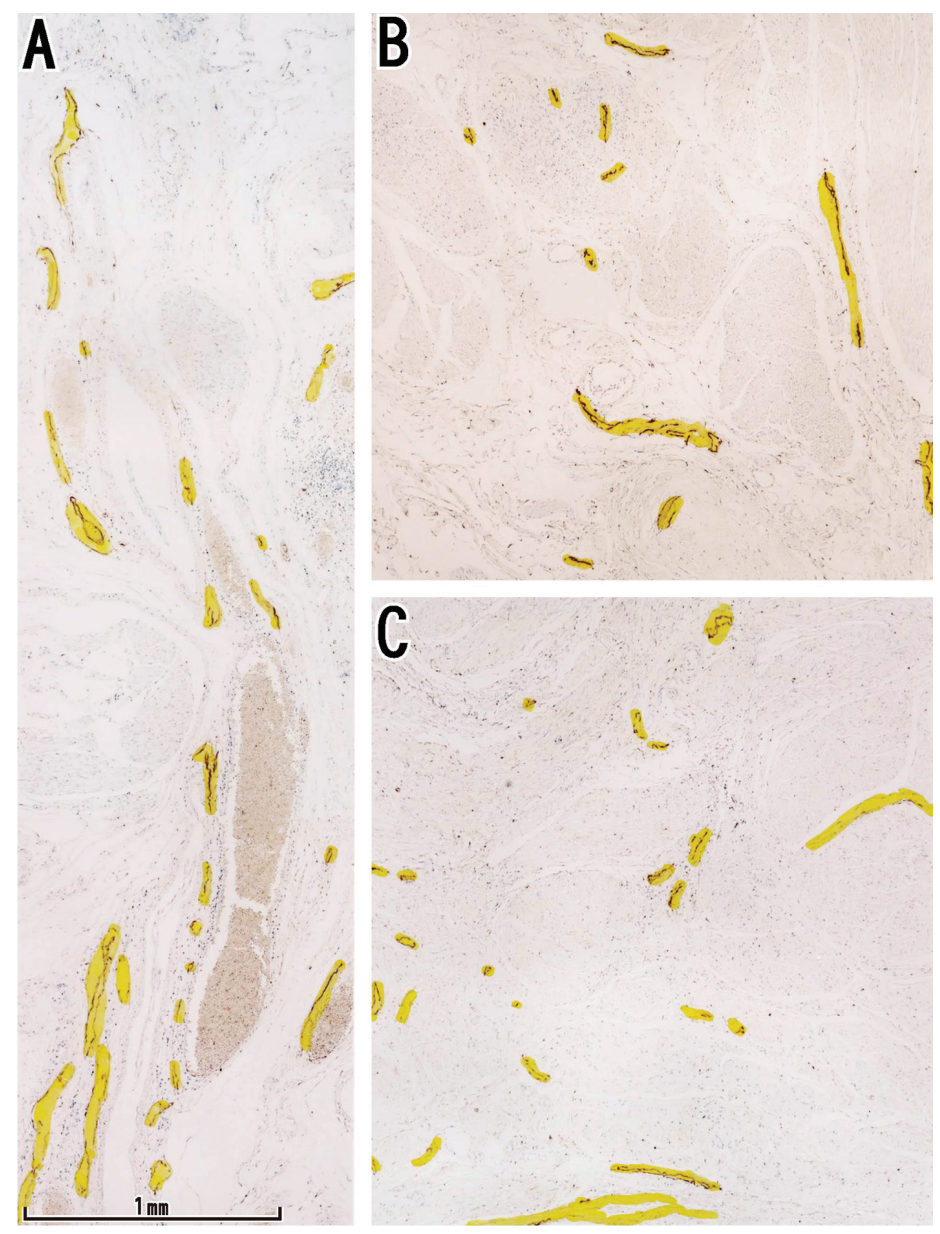

Figure 5. Lymphatic vessels in the smooth muscles of the bladder; $\mathbf{A}$. A higher-magnification view of the square in Figure 1B (an 80-year-old woman), displays lymphatic vessels (arrows) along a vein draining to the external surface of the bladder; $\mathbf{B}$. Corresponding to the square in Figure 1A (an 83-year-old woman), exhibits lymphatic vessels along and around loosely arranged smooth muscle bundles; C. Corresponding to the square in Figure $1 \mathrm{~F}$ (a 73-year-old woman), the vessels are scattered among tightly arranged smooth muscle bundles.

surgery $[2,25]$. However, the future application of robot-assisted surgery for uterine cancer may be difficult when it includes complete resection of LVs along the uterine artery and superficial uterine vein, due to the tight nature of the connective sheath.

\section{CONCLUSIONS}

Since most of the LVs along the uterine artery and superficial uterine vein were embedded in the tight connective tissue sheath of the artery and vein, surgical separation of the LVs near and around the uterus seemed to be difficult in women who had children with vaginal delivery.

\section{REFERENCES}

1. Bidus MA, Caffrey AS, You WB, Amezcua CA, Chernofsky MR, Barner R, Seidman J, Rose GS (2008) Cervical biopsy and excision procedure specimens lack sufficient predictive value for lymphvascular space invasion seen at hysterectomy for cervical cancer. Am J Obstet Gynecol, 199: 151.e1-151.e4.

2. D'Annibale A, Pende V, Pernazza G, Monsellato I, Mazzocchi P, Lucandri G, Morpurgo E, Contardo T, Sovernigo G
(2011) Full robotic gastrectomy with extended (D2) lymphadenectomy for gastric cancer: surgical technique and preliminary results. J Surg Res, 166: e113-e120.

3. Ercoli A, Delmas V, lannone V, Fagotti A, Fanfani F, Corrado G, Ferradina G, Scambia G (2010) The lymphatic drainage of the uterine cervix in adult fresh cadavers: anatomy and surgical implications. Eur J Surg Oncol, 36: 298-303.

4. Fujii S, Takakura K, Matsumura N, Higuchi T, Yura S, Mandai M, Baba T. (2007) Precise anatomy of the vesico-uterine ligament for radical hysterectomy. Gynecol Oncol, 104: 186-191.

5. Fujii S, Takakura K, Matsumura N, Higuchi T, Yura S, Mandai M, Baba T, Yoshioka S (2007) Anatomic identification and functional outcomes of the nerve sparing Okabayashi radical hysterectomy. Gynecol Oncol, 107: 4-13.

6. Fukuda H, Yamada T, Kamata S, Saitoh H (2000) Anatomic distribution of intraprostatic lymphatics: implications for the lymphatic spread of prostate cancer: a preliminary study. Prostate, 44: 322-327.

7. Fukunaga $M$ (2005) Expression of D2-40 in lymphatic endothelium of normal tissues and in vascular tumors. Histopathology, 46: 396-402.

8. Hoffman MS, Williams V, Salihu HM, Gunasekaran S, Sayer RA, Hakam A, Roberts WS (2008) The vascular portion of the cardinal ligament: surgical significance during radical hysterectomy for cervical cancer. A J Obstet Gynecol, 199: e1-e7. 
9. Ishikawa $Y$, Akasaka $Y$, Kiguchi $H$, Akishima-Fukasawa $Y$, Hasegawa $T$, Ito $K$, Kimura-Matsumoto $M$, Ishiguro $S$, Morita H, Sato S, Soh S, Ishii T (2006) The human renal lymphatics under normal and pathological conditions. Histopathology, 49: 265-273.

10. Lee KB, Lee JM, Park CY, Lee KB, Cho HY, Ha SY (2006) Lymph node metastasis and lymph vascular space invasion in microinvasive squamous cell carcinoma of the uterine cervix. Int J Gynecol Cancer, 16: 1184-1187.

11. Levenback C, Coleman RL, Burke TW, Lin WM, Erdman W, Deavers M, Delpassand ES (2002) Lymphatic mapping and sentinel node identification in patients with cervix cancer undergoing radical hysterectomy and pelvic lymphadenectomy. J Clin Oncol, 20: 688-693.

12. Lopes LA, Nicolau SM, Baracat FF, Baracat EC, Goncalves WJ, Santos HV, Lopes RG, Lippi UG (2007) Sentinel lymph node in endometrial cancer. Int J Gynecol Cancer, 17: 1113-1117.

13. Miller JL, Watkin KL, Chen MF (2002) Muscle, adipose, and connective tissue variations in intrinsic musculature of the adult human tongue. J Speech Lang Hear Res, 45: 51-65.

14. Mota F, Vergote I, Trimbos JB, Amant F, Siddiqui N, Del Rio A, Verheijen R, Zola P (2008) Classification of radical hysterectomy adopted by the Gynecological Cancer Group of the Europian Organization for Research and Treatment of Cancer. Int J Gynecol Cancer, 18: 1136-1138.

15. Pedrazzoli S, Pasquail C, Sperti C (2005) Extent of lymphadenectomy in the resection of pancreatic cancer. Analysis of the existing evidence. Rocz Akad Med Bialymst, 50: 85-90.

16. Pissas A, Papamiltiades M (1981) Our experience on anatomical injections of lymphatic vessels. Lymphology, 14: 145-148.

17. Querleu D, Morrow CP (2008) Classification of radical hysterectomy. Lancet Oncol, 9: 297-303.

18. Reiffenstuhl G (1964) The lymphatics of the female genital organs. Lippincott, Philadelphia.

19. Red-Horse K (2008) Lymphatic vessel dynamics in the uterine wall. Placenta, 29: S55-S59.

20. Riquet M, Le Pimpec Barthes F, Souilamas R, Hidden G (2002) Thoracic duct tributaries from intrathoracic organs. Ann Thorac Surg, 73: 892-899.

21. Rofers PA, Donoghue JF, Walter LM, Girling JE (2009) Endometrial angiogenesis, vascular maturation, and lymphangiogenesis. Reprod Sci, 16: 147-151.

22. Rouvière H (1981) Anatomie des lymphatiques de L'Homme. Masson, Paris.

23. Sawai K, Takahashi S, Kato G, Takenaka A, Tokuda H, Hagiwara A, Takahashi T (1985) Endoscopic injection of activated carbon particle $(\mathrm{CH} 44)$ for extended radical lymphadenectomy of gastric cancer. Jpn J Gastroenterol Surg, 18: 912-917.

24. Smith JR, Boyle DC, Corless DJ, Unger L, Lawson AD, Del Priore G, McCall JM, Lindsay I, Bridges JE (1997) Abdominal radical trachelectomy: a new surgical technique for the conservative management of cervical carcinoma. $\mathrm{Br} J$ Obstet Gynecol, 104: 1196-1200.

25. Song J, Oh SJ, Kang WH, Hyung WJ, Choi SH, Noh SH (2009) Robot-assisted gastrectomy with lymphnode dissection for gastric cancer: lessons learned from an initial 100 consecutive procedures. Ann Surg, 249: 927-932.

26. Suga K, Ogasawara N, Yuan Y, Okada M, Matsunaga N (2003) Visualization of breast lymphatic pathways with an indirect CT lymphangiography using a nonionic monometric contrast medium iopamidol: preliminary results. Invest Radiol, 38: 73-84.

27. Tamakawa M, Murakami G, Takashima K, Kato T, Hareyama M (2003) Fascial structures and autonomic nerves in the female pelvis: a study using macroscopic slices and their corresponding histology. Anat Sci Int, 78: 228-242.

28. Ueki M (1991) Histologic study of endometriosis and examination of lymphatic drainage in and from the uterus. Am J Obstet Gynecol, 165: 201-209.

29. Ueno H, Mochizuki H, Tamakuma S (1998) Prognostic significance of extranodal microscopic foci discontinuous with primary lesion in rectal cancer. Dis Colon Rectum, 41: 55-61.

30. Watanabe $Y$, Satou T, Nakai H, Etoh T, Dote K, Fujinami N, Hoshiai H (2010) Evaluation of parametrial spread in endometrial carcinoma. Obstet Gynecol, 116: 1027-1034.

31. Weber SK, Sauerwald A, Polcher M, Braun M, Debald M, Serce NB, Kuhn W, Brunagel-Walgenbach G, Rudlowski C (2012) Detection of lymphovascular invasion by D2-40 (podoplanin) immunoexpression in endometrial cancer. Int J Gynecol Cancer, 22: 1442-1448.

32. Weidner N, Semple JP, Welch WR, Folkman J (1991) Tumor angiogenesis and metastasis-correlation in invasive breast carcinoma. N Eng J Med, 324: 1-8.

33. Yabuki Y, Asamoto A, Hoshiba T, Nishimori H, Nishikawa Y, Nakajima T (2000) Radical hysterectomy: an anatomic evaluation of parametrial dissection. Gynecol Oncol, 77: 155-163.

34. Yajin S, Murakami G, Takeuchi H, Hasegawa T, Kitano H (2009) A normal configuration and interindividual differences in intramural lymphatics of the esophagus. J Thorac Cardiovasc Surg, 137: 1406-1414.

35. Zöltzer H (2007) Open interfaces in initial lymphatics: a methodological artifact? Lymphology, 40: 163-171. 